\title{
Comparative study of IgA nephropathy with and without crescents
}

C. Bitencourt-Dias ${ }^{1}$, M. Bahiense-Oliveira ${ }^{1}$,

L.B. Saldanha ${ }^{2}$,

R.T. Barros ${ }^{1}$ and

V. Woronik ${ }^{1}$
Disciplinas de ${ }^{1}$ Nefrologia and ${ }^{2}$ Patologia, Hospital das Clínicas, Universidade de São Paulo, São Paulo, SP, Brasil

\section{Correspondence}

Cristiane Bitencourt

R. Cubatão, 584/52

04013-002 São Paulo, SP

Brasil

Fax: +55-11-5904-2638

E-mail: cristianebitencourt@uol.com.br

Publication supported by FAPESP

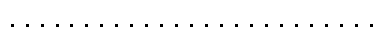

Received October 14, 2002

Accepted May 20, 2004

\begin{abstract}
Glomerular crescents were analyzed as a prognostic factor in retrospectively reviewed data from 144 patients with biopsy-proven IgA nephropathy. Crescents were found in $26(18 \%)$ patients, and detected in 2 to $100 \%$ of glomeruli in each specimen. In $5 \%$ of the patients more than $50 \%$ of the glomeruli were affected. Thirty patients with IgA nephropathy without crescents were studied as a control group. Mean age was $30.3 \pm 9.4$ and $30.2 \pm 12.0$ years for the patients with and without crescents, respectively, and males prevailed in both groups. The length of follow-up was $23.2 \pm 41.6$ months for patients with crescents and $29.3 \pm 35.3$ months for patients without crescents. Eighty percent of the patients with crescents were hypertensive, compared to $27 \%$ of the non-crescent control group $(\mathrm{P}<0.05)$. Mean serum creatinine at the time of diagnosis was $3.9 \pm 2.9$ and $1.9 \pm 2.1$ $\mathrm{mg} / \mathrm{dl}$ for the patients with and without crescents, respectively. Initial urinary protein excretion was higher in patients with crescents $(4.6 \pm$ 3.5 vs $1.2 \pm 0.9 \mathrm{~g} /$ day; $\mathrm{P}<0.05)$. At the end of follow-up 17 patients (77.3\%) from the crescent group and $3(11.1 \%)$ from the non-crescent group had end-stage renal disease $(\mathrm{P}<0.0001)$. The presence of crescents was associated with higher levels of initial serum creatinine and urinary protein excretion, and a higher frequency of hypertension and progression to end-stage renal disease.
\end{abstract}

\section{Introduction}

$\operatorname{Ig}$ A nephropathy is said to be the most common form of primary glomerulonephritis worldwide (1), especially in Europe and some countries in Asia and Oceania, where 20 to $47 \%$ of the kidney biopsies receive this diagnosis (2-5). In the Americas, IgA nephropathy is found in approximately $10 \%$ of the cases biopsied in Uruguay, USA and Brazil (6-8). This frequency can be higher
Key words

- IgA nephropathy

- Crescents

- Renal failure

- End-stage renal disease

- Creatinine (up to $29 \%$ ) among patients with hematuria and proteinuria without nephrotic syndrome (8). In addition to genetic predisposition and environmental factors, clinical presentation at the time of the biopsy may influence the prevalence of the disease.

In 40 to $50 \%$ of patients, recurrent macroscopic hematuria is the main clinical sign of IgA nephropathy, which usually coincides with mucosal infection or exercise, notably in younger patients (9). Despite intensive 
investigation by several groups, a widely accepted hypothesis for the pathogenesis of IgA nephropathy has not yet emerged. Some studies have correlated mucosal airway infection with hyperactivity of the immune system, leading to an overproduction of this $\operatorname{Ig} \mathrm{A} 1$ and $\operatorname{Ig} \mathrm{A} 2$, and elevation of serum $\operatorname{IgA}$ levels and kidney tissue depositon (10). Moreover, 35 to $50 \%$ of patients with $\operatorname{IgA}$ nephropathy have elevated serum IgA levels, especially of the IgA1 subclass, derived from bone marrow (11). IgA1 is the subclass found in renal tissue (notably in the mesangium). Whether in IgA nephropathy circulating IgA1 is bound to antigens in the form of immune complexes is still a controversial issue, in spite of the well-known recurrence of acute disease after mucosal infectious episodes. Circulating IgA from patients with IgA nephropathy exhibits abnormal glycosylation that could enhance its affinity for mesangial receptors, leading to mesangial deposition (12). Furthermore, impaired hepatic clearance of IgA1 with this glycosylation defect may also contribute to the elevation of serum levels of IgA (13).

Microscopic hematuria with or without proteinuria can be found in 30 to $50 \%$ of cases and its detection depends on urine testing. Nephrotic syndrome and renal failure are unusual (5\%), although at our institution $25 \%$ of the patients with IgA nephropathy present nephrotic syndrome (14). Renal failure and hypertension are common, being detected in 59 and $53 \%$ of our patients, respectively (14).

End-stage renal disease (ESRD) can develop in 20 to $40 \%$ of patients with IgA nephropathy at 10 to 20 years of follow-up $(9,15)$. Most studies have identified the extent of proteinuria and renal insufficiency as the most powerful predictors of a poor outcome (16). Male gender, young age at the onset of the disease, absence of recurrent macroscopic hematuria, persistent microscopic hematuria, and hypertension are also implicated as risk factors for a worse prog- nosis (15). Diffuse proliferative glomerulonephritis and the extent of glomerulosclerosis, interstitial fibrosis and crescents are considered to be markers of a poor prognosis $(9,15)$. However, when multivariate analyses are performed to control serum creatinine, these markers are not considered to be independent risk factors for a worse outcome $(15,17)$. However, comparisons among studies concerning prognosis are limited. Methodological approaches vary, and the influence of different treatment regimens cannot be assessed.

In view of the high frequency of IgA nephropathy among our patients without nephrotic syndrome, and the elevated prevalence of renal failure in patients with IgA nephropathy at our institution, the objective of the present study was to describe the frequency of crescents and the renal outcome in patients with IgA nephropathy treated at University Hospital, Faculty of Medicine, University of São Paulo.

\section{Patients and Methods}

Between January 1980 and January 2001, 144 patients with biopsy-proven IgA nephropathy were retrospectively identified in a 2000-bed tertiary care complex in São Paulo. Patients older than 14 years and without clinical evidence of systemic disease were included. All patients were followed by the Nephrology Division staff, and received only diuretics and anti-hypertensive medication as needed. Data about demographic variables, hypertension, serum creatinine, urinary protein excretion, and the presence of crescents in the renal biopsy were obtained from the medical charts. Specimens with less than 6 glomeruli were excluded from analysis. The end of follow-up was the last visit of the patient to the $\mathrm{Ne}$ phrology Division.

Of the 144 cases with IgA nephropathy, 26 had crescents in renal tissue. We selected another 30 patients of similar age and sex 
among patients without crescents for comparison of demographic data, diagnosis of hypertension, serum creatinine, and proteinuria, at the time of diagnosis. At the end of follow-up, serum creatinine and the need for dialysis were also determined for both groups.

\section{Statistical analysis}

Data were compared by the chi-square test or Fisher exact test when appropriate and mean data $( \pm \mathrm{SD})$ were compared by the Student $t$-test, with the level of significance set at $\mathrm{P}=0.05$.

\section{Results}

Crescents were found in 18\% (26/144) of the IgA nephropathy patients and were detected in 2 to $100 \%$ of the glomeruli in each specimen, although in only a small proportion of cases $(5 \%)$ did they affect more than $50 \%$ of the glomeruli. Patient data are presented in Table 1. The mean age of patients with and without crescents was $30.3 \pm 9.4$ and $30.2 \pm 12.0$ years, respectively, and males predominated in both groups. The duration of follow-up was $23.2 \pm 41.6$ months and $29.3 \pm 35.3$ months for patients with and without crescents, respectively. Eighty percent $(12 / 15)$ of the patients with crescents were hypertensive, in contrast to $27 \%(3 / 11)$ of the patients without crescents $(\mathrm{P}<0.05)$. Data concerning hypertension were not available for 30 patients. Mean serum creatinine values at the time of biopsy (initial creatinine) were $3.9 \pm 2.9$ and $1.9 \pm 2.1 \mathrm{mg} / \mathrm{dl}$ for the patients with and without crescents, respectively $(\mathrm{P}<0.05)$. Initial urinary protein excretion was higher in patients with crescents $(4.6 \pm 3.5 \mathrm{~g} /$ day $)$ than in the patients without crescents $(1.2 \pm 0.9 \mathrm{~g} /$ day $), \mathrm{P}<0.05$.

Serum creatinine values at the end of follow-up (final creatinine) were also different between groups: $8.0 \pm 3.7 v s 2.2 \pm 2.8$ $\mathrm{mg} / \mathrm{dl}$ for crescent and non-crescent patients ( $P<0.0001)$. At the end of follow-up $40 \%$ of

the patients had ESRD: 17 (77.3\%) patients with crescents required dialysis therapy compared to $3(11.1 \%)$ non-crescent patients ( $\mathrm{P}$ $<0.0001)$. Renal survival data were not available for 4 patients with crescents and for 3 patients without crescents.

\section{Discussion}

Formerly considered to be as a benign entity, IgA nephropathy can progress to ESRD in 20 to $40 \%$ of patients, depending on the population studied $(9,15)$. In Australia/New Zealand IgA nephropathy is as common as diabetic nephropathy as a single etiology of ESRD and is the leading cause of ESRD among Japanese patients with glomerulonephritis $(5,18)$. In Brazil there are no available data about IgA nephropathy as a cause of ESRD.

However, a recent report by the Registry of Glomerulonephritis of the State of São Paulo (19) showed that IgA nephropathy is a common glomerular disease found in $17.7 \%$ of biopsied patients. The institutions comprising this Registry are specialized in nephrology and nephropathology. Thus, these data are not representative of the frequency of IgA nephropathy in the health care services of Brazil as a whole. Underdiagnosis of IgA nephropathy might be an important issue in our country. There is no screening policy for renal disease in Brazil and only symptomatic

Table 1. Clinical and functional characteristics of IgA nephropathy patients with crescents and without crescents.

With crescents

No. of patients

Age (years)

Gender (male:female)

Time of follow-up (months)

Initial serum creatinine $(\mathrm{mg} / \mathrm{dl})$

Final serum creatinine (mg/dl)

Proteinuria (g/24 h)

Hypertension

Data are reported as means $\pm \mathrm{SD}$. ${ }^{*} \mathrm{P} \leq 0.05$ compared to patient with crescents (Student $t$-test).

Without crescents 30

$\begin{array}{cc}30.3 \pm 9.4 & 30.2 \pm 12 \\ 1.9: 1.0 & 2.0: 1.0 \\ 23.2 \pm 41.6 & 29.3 \pm 35.3 \\ 3.9 \pm 2.9 & 1.9 \pm 2.1^{*} \\ 8.0 \pm 3.7 & 2.2 \pm 2.8^{*} \\ 4.6 \pm 3.4 & 1.2 \pm 0.9^{*} \\ 12(15) 80 \% & 3(11) 27 \%^{*}\end{array}$
$2 \pm 12$

$3.3 \pm 35.3$

$1.2 \pm 0.9$ 
and/or more clinically compromised patients reach the health care services and can be identified. There are only few kidney biopsy centers and in most of them immunofluorescence microscopy, necessary for the diagnosis of IgA nephropathy (20), is not available. Therefore, the impact of IgA nephropathy on the prevalence of glomerular diseases and among ESRD patients in Brazil warrants further investigation.

In contrast to other nephrology centers $(9,15)$, our patients with IgA nephropathy present a high frequency of renal failure and hypertension. The high occurrence of progression to ESRD among our IgA nephropathy patients probably reflects the more severe cases of $\operatorname{IgA}$ nephropathy referred to our service. The patients with crescents in our population had a higher prevalence of hypertension, proteinuria and renal failure, recognized as the most powerful risk factors for progression to $\operatorname{ESRD}(9,15,18)$. These results are similar to other reports. Hogg et al. (21) found crescents in $20 \%$ of 218 pediatric patients with IgA nephropathy. After at least 4 years of follow-up, $42 \%$ of the patients that reached ESRD had crescents in their biopsies, in contrast to $13 \%$ of dialysisfree patients. Yoshikawa et al. (22) showed that the percentage of crescents was five times higher in patients with IgA nephropathy and a glomerular filtration rate $<60 \mathrm{ml}$ $\min ^{-1}\left(1.74 \mathrm{~m}^{2}\right)^{-1}$.

Haas et al. (7), studying the effect of the histologic parameters of IgA nephropathy and prognosis (renal survival) by univariate analysis, showed that the presence of crescents was associated with a worse prognosis in patients with IgA nephropathy characterized by focal proliferative glomerulonephritis. In the multivariate analysis, however, when controlled for serum creatinine, the presence of crescents had no independent influence on renal survival. The only parameters independently associated with poor outcome were proteinuria $>2$ g/day and hypertension (7).

Treatment of IgA nephropathy has been changing in recent years. Since angiotensin II plays an important role in the pathogenesis of proteinuria, blockade of the renin-angiotensin system is the therapy of choice for patients with proteinuric nephropathy (23). Even in patients without hypertension, the use of angiotensin-converting enzyme inhibitors and AT1-receptor antagonists, alone or in combination, reduces urinary protein excretion and slows the decline in renal function (24).

The treatment of IgA nephropathy has become more aggressive regarding the use of immunosuppression. According to Pozzi et al. (25), patients with creatinine levels of $1.5 \mathrm{mg} / \mathrm{dl}$ and proteinuria between 1 and 3.5 $\mathrm{g} / 24 \mathrm{~h}$ should be treated with methylprednisolone followed by oral prednisone for at least six months. Ballardie and Roberts (26) treated patients with loss of renal function (creatinine $>1.5$ ) with prednisone, cyclophosphamide and azathioprine, and obtained a significant reduction in the development of renal disease during the three years of follow-up. Regarding IgA nephropathy with crescents, other investigators have proposed the use of immunosuppression with prednisone, cyclophosphamide and azathioprine for at least six months $(27,28)$. It was not possible to evaluate the impact of any treatment on our patients since this was a retrospective study regarding a period (19802001) during which different therapeutic approaches were used.

In conclusion, patients with crescents developed a high frequency of ESRD at the end of follow-up at our institution. The presence of crescents was associated with higher levels of initial serum creatinine and urinary protein excretion, as well as with the frequency of hypertension and progression to ESRD. 


\section{References}

1. Julian BA, Waldo B, Rifai A \& Mestecky J (1988). IgA nephropathy, the most common glomerulonephritis worldwide. American Journal of Medicine, 4: 129-132.

2. D'Amico G (1987). The commonest glomerulonephritis in the world: IgA nephropathy. Quarterly Journal of Medicine, 64: 709-727.

3. Simon P, Ramée MP, Autuly V, Laruelle E, Charasse C, Cam G \& Ang KS (1994). Epidemiology of primary glomerular diseases in a French region. Variations according to period and age. Kidney International, 46: 192-198.

4. Schena FP (1997). Italian group of renal immunopathology. Survey of the Italian registry of renal biopsies. Frequency of the renal diseases for 7 consecutive years. Nephrology, Dialysis, Transplantation, 12: 418-426.

5. Research Group on Progressive Chronic Renal Disease (1999). Nationwide and long-term survey of primary glomerulonephritis in Japan as observed in 1,850 biopsied cases. Nephron, 82: 205-223.

6. Mazzuchi N \& Di Martino LA (1997). Epidemiología de las glomerulopatias primárias en el Uruguay. Archivio di Medicina Interna, 19: 21-26.

7. Haas M, Meehan SM, Kattison TG \& Spargo BH (1997). Changing etiologies of unexplained adult nephrotic syndrome: a comparison of renal biopsy findings from 1976-1979 and 1995-1997. American Journal of Kidney Diseases, 30: 621-631.

8. Bahiense-Oliveira M, Malafronte P \& Barros RT (2002). Aspectos epidemiológicos das glomerulopatias no Brasil. In: Cruz J, Mazzarolo-Cruz HM \& Barros RT (Editors), Atualidades em Nefrologia 7. Sarvier, São Paulo, SP, Brazil, 73-77.

9. Floege J \& Feehally J (2000). IgA nephropathy: recent developments. Journal of the American Society of Nephrology, 11: 23952403.

10. Galla JH (1995). IgA nephropathy. Kidney International, 47: 377-387.

11. Noris M \& Remuzzi G (1999). IgA nephropathy: a stem cell disease? Kidney International, 56: 1964-1966.

12. Allen $A C$, Bailet EM, Brenchley PE, Buck KS, Barratt $J$ \& Feehally $J$ (2001). Mesangial IgA1 in IgA nephropathy exhibits aberrant Oglycosylation: observations in three patients. Kidney International, 60: 969-973.

13. Roccatello D, Picciotto G, Torchio M et al. (1993). Removal systems of immunoglobulin A and immunoglobulin A containing complexes in IgA nephropathy and cirrhosis patients. The role of asiliglycoprotein receptors. Laboratory Investigation, 69: 714-723.

14. Bahiense-Oliveira M, Mota ELA, Saldanha LB, Penna DO, Barros RT \& Romão Jr JE (2004). Primary glomerular diseases in Brazil: is the frequency of focal and segmental glomerulosclerosis increasing? Clinical Nephrology (in press).

15. D'Amico G (2000). Natural history of idiopathic IgA nephropathy: role of clinical and histological prognostic factors. American Journal of Kidney Diseases, 36: 227-237.

16. Bartosik LP, Lajoie G, Sugar L \& Cattran DC (2001). Predicting progression in IgA nephropathy. American Journal of Kidney Diseases, 38: 728-735.

17. Haas M (1997). Histologic subclassification of IgA nephropathy: a clinicopathologic study of 244 cases. American Journal of Kidney Diseases, 29: 829-842.

18. Maisonneuve P, Agodoa L, Gallert R et al. (2000). Distribution of primary renal diseases leading to end-stage renal failure in the United States, Europe and Australia/New Zealand: results from a comparative study. American Journal of Kidney Diseases, 35: 157163.

19. Registro Paulista de Glomerulopatias (2001). Brazilian glomerulonephritis registry: analysis of a regional multicentre study in State of São Paulo. Journal of the American Society of Nephrology, 12: 114A.

20. Emancipator SN (1998). IgA nephropathy and Henoch-Schönlein syndrome. In: Jennette JC, Olson JL, Schwartz MW \& Silva FG (Editors), Heptinstall's Pathology of the Kidney. Lippincott-Raven, Philadelphia, PA, USA.

21. Hogg RJ, Silva FG, Wyatt RJ, Reisch JS, Argyle JC \& Savino DA (1994). Prognostic indicators in children with IgA nephropathy Report of the Sowthwest Pediatric Nephrology Study Group. Pediatric Nephrology, 8: 15-20.

22. Yoshikawa N, Ito H \& Nakamura H (1992). Prognostic indicators in childhood IgA nephropathy. Nephron, 60: 60-67.

23. Gruppo Italiano di Studi Epidemiologici in Nefrologia (GISEN) (1998). Randomized placebo-controlled trial of effect of ramipril on decline in glomerular filtration rate and risk of terminal renal failure in proteinuric, non-diabetic nephropathy. Lancet, 352: 1252-1256.

24. Russo D, Minutolo R, Pisani A, Esposito R, Signoriello G, Andreucci M \& Balletta MM (2001). Coadministration of losartan and enalapril exerts additive antiproteinuric effect in IgA nephropathy. American Journal of Kidney Diseases, 38: 18-25.

25. Pozzi C, Bolasco PG, Fogazzi GB, Androlli S, Altieri P, Ponticelli C \& Locatelli $F$ (1999). Corticosteroids in IgA nephropathy: A randomised controlled trial. Lancet, 353: 883-887.

26. Ballardie FW \& Roberts IS (2002). Controlled prospective trial of prednisolone and cytotoxics in progressive IgA nephropathy. Journal of the American Society of Nephrology, 13: 142-148.

27. Mclntyre CW, Fluck RJ \& Lambie SH (2001). Steroid and cyclophosphamide therapy for IgA nephropathy associated with crescenteric change: an effective treatment. Clinical Nephrology, 56: 193-198.

28. Tumlin JA, Lahavichan V \& Hennigar R (2003). Crescentic, proliferative IgA nephropathy: clinical and histological response to methylprednisolone and intravenous cyclophosphamide. Nephrology, Dialysis, Transplantation, 18: 1321-1329. 